B. Gomes (2020): “Uma lucerna grega arcaica da necrópole do Olival do Senhor dos Mártires (Alcácer do Sal, Portugal)", Spal 29.1: 79-91. DOI: http://dx.doi.org/10.12795/spal.2020.i29.03

\title{
UMA LUCERNA GREGA ARCAICA DA NECRÓPOLE DO OLIVAL DO SENHOR DOS MÁRTIRES (ALCÁCER DO SAL, PORTUGAL)
}

\section{AN ARCHAIC GREEK LAMP FROM THE NECROPOLIS OF OLIVAL DO SENHOR DOS MÁRTIRES (ALCÁCER DO SAL, PORTUGAL)}

\author{
FRANCISCO B. GOMES \\ Uniarq. Faculdade de Letras. Universidade de Lisboa. \\ Alameda da Universidade, 1600-214 Lisboa, Portugal. \\ Correo-e: franciscojbgomes@gmail.com (D) http://orcid.org/0000-0003-0664-6374. \\ Research ID: <https://publons.com/researcher/AAE-7217-2019>
}

\begin{abstract}
Resumo: Entre os materiais exumados por Vergílio Correia na necrópole do Olival do Senhor dos Mártires (Alcácer do Sal) durante a década de 1920 conta-se uma lucerna ainda inédita. Pelas suas características morfológicas e produtivas esta peça inscreve-se no âmbito do repertório lychnológico grego arcaico, podendo identificar-se como uma produção coríntia. O contexto desta peça, exumada na Sepultura 98 da necrópole, confirma esta adscrição crono-tipológica, permitindo atribuir-lhe uma datação do primeiro quartel do século $\mathrm{V}$ a.n.e.. Este exemplar pode assim enquadrar-se no contexto do comércio de produtos gregos tardo-arcaicos no actual território peninsular.
\end{abstract}

Palavras-chave: cerâmica grega; iluminação; Corinto; práticas funerárias; I Idade do Ferro.

\section{CONSIDERAÇÕES PRÉVIAS: A PEÇA E A SUA DESCOBERTA}

Apesar da sua precoce identificação, ocorrida ainda nos finais do século XIX (Silva 1875), a necrópole do Olival do Senhor dos Mártires (OSM), utilizada como espaço funerário pela comunidade de Alcácer do Sal
Abstract: Among the material exhumed by Vergílio Correia in the necropolis of Olival do Senhor dos Mártires (Alcácer do Sal) during the 1920's there is an unpublished lamp which by its morphological and productive characteristics can be considered an archaic Greek production, specifically from Corinth. The context of this piece, retrieved in the necropolis's Tomb 98, confirms this chrono-typological attribution and indicates this piece must be dated to the first quarter of the fifth century B.C.E.. This lamp can therefore be analysed in the framework of the trade of late archaic Greek products to the Iberian Peninsula.

Key words: Greek pottery; illumination; Corinth; funerary practices; Early Iron Age.

entre os inícios da Idade do Ferro e a Época Romana Republicana (fig. 1), não foi objecto de uma exploração sistemática até bastante mais tarde.

Com efeito, as primeiras intervenções arqueológicas realizadas no sítio datam já da década de 1920, durante a qual Vergílio Correia conduziu quatro extensas campanhas de escavação no OSM que permitiram pela 


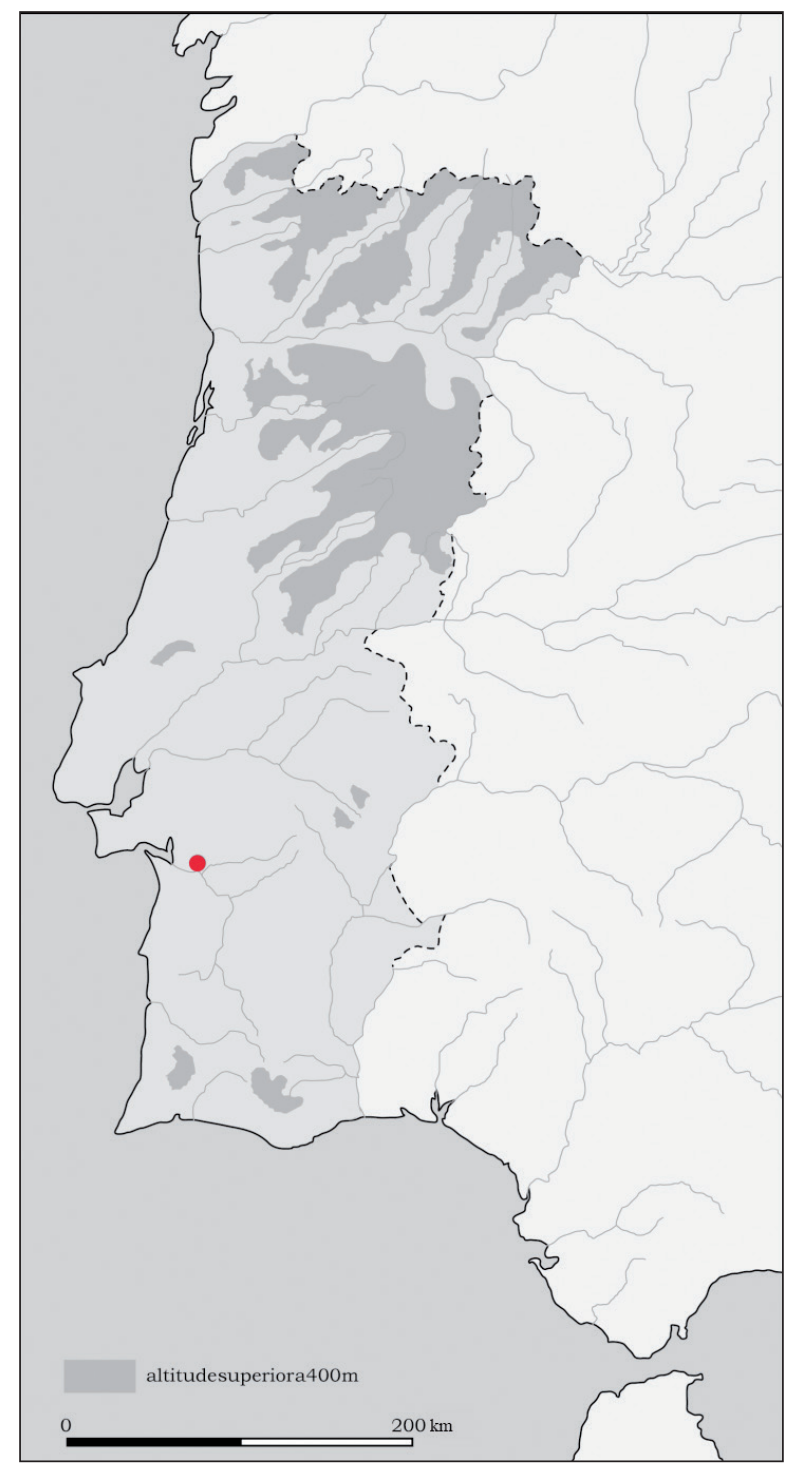

Figura 1. Localização do OSM no actual território português (base cartográfica: Professor Victor S. Gonçalves).

primeira vez caracterizar de forma relativamente detalhada as diversas modalidades funerárias ali representadas (Correia 1972 [1925]; Correia 1972 [1928]).

Infelizmente, os resultados destas intervenções pioneiras nunca chegaram a ser sistematicamente publicados. Os trabalhos dados à estampa por Vergílio Correia (ibidem), apesar do seu carácter preliminar, constituem ainda assim um dos elementos chave para a compreensão da diversa e complexa sequência funerária da necrópole (Gomes 2016; no prelo).

Além desses fundamentais contributos, os trabalhos do Professor da Universidade de Coimbra legaram-nos um extenso conjunto de materiais arqueológicos hoje distribuídos entre o Museu Nacional de Arqueologia, em Lisboa, e o Museu Didáctico do Instituto de Arqueologia da Universidade de Coimbra (MDIA). Esta última instituição conserva um conjunto de elementos particularmente expressivos (cf. Vilaça 2016) que foram já objecto de estudo, parcial ou total, em múltiplas ocasiões (Brito 1968, Schüle 1969, Paixão 1970, Ponte 1985, Rouillard et al. 1989, Frankenstein 1997, Gomes 2016).

Entre este lote de materiais levado por Vergílio Correia para Coimbra e hoje custodiado pelo MDIA conta-se uma lucerna em bastante bom estado de conservação (fig. 2) que, apesar do interesse dedicado ao resto do conjunto do OSM ali depositado, escapou até ao momento à atenção da investigação.

Esta peça, recolhida na última campanha conduzida por aquele investigador no OSM em 1927, apresenta uma morfologia particular, muito invulgar no território peninsular, o que poderá ter dificultado o seu correcto enquadramento crono-cultural, justificando assim de alguma forma a sua sistemática não inclusão nos estudos antes citados.

Atendendo à sua morfologia e às suas características produtivas, esta peça pode integrar-se no quadro da produção lychnológica grega arcaica, constituindo assim um elemento a somar aos raros exemplares de cerâmicas gregas documentados no Ocidente Peninsular anteriores à fase clássica (Arruda 2019). Parece portanto importante dar a conhecer esta lucerna, insistindo nas suas características formais e produtivas, bem como discutir a sua posição dentro do diverso e complexo panorama tipológico das mais antigas lucernas gregas.

O estudo exaustivo dos materiais exumados por Vergílio Correia no OSM, recentemente concluído (Gomes 2016), permite igualmente reconstruir de forma muito aproximada o contexto primário desta peça, delimitando o seu enquadramento histórico e permitindo uma breve discussão da sua posição no quadro do comércio de produtos gregos arcaicos na Península Ibérica.

\section{A LUCERNA GREGA ARCAICA DO OSM: MORFOLOGIA, CLASSIFICAÇÃO E CARACTERÍSTICAS PRODUTIVAS}

Ao tratar-se de um elemento raro nos repertórios ceramológicos da Península Ibérica em geral, e do Extremo Ocidente em particular, a correcta interpretação da lucerna aqui estudada implica antes de mais uma exposição detalhada das suas características formais e produtivas que permita cotejá-la com os dados de 


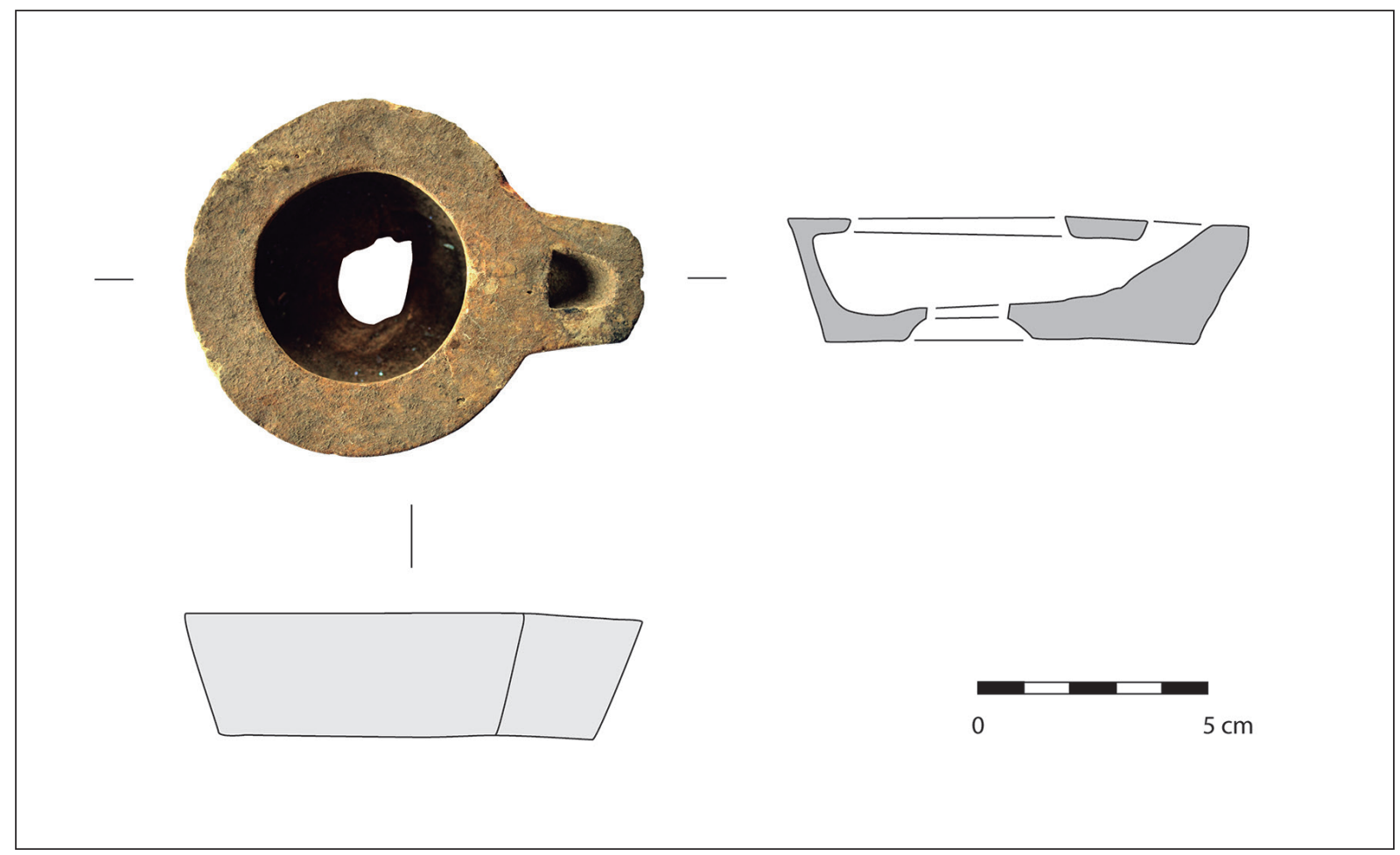

Figura 2. Lucerna grega arcaica do Olival do Senhor dos Mártires.

outras áreas do Mediterrâneo onde as lucernas de tipos afins à da que aqui nos ocupa são mais frequentes e se encontram mais bem estudadas.

Do ponto de vista morfológico, esta peça corresponde a um modelo de lucerna com depósito aberto, sem disco (fig. 2). O seu comprimento máximo é de $10 \mathrm{~cm}$ e o diâmetro do seu depósito é de $7,8 \mathrm{~cm}$; a sua altura máxima é de $2,7 \mathrm{~cm}$.

A base desta peça é plana, sem pé, contando não obstante com uma concavidade central hoje fracturada, o que impede a restituição exacta da forma como a mesma se desenvolveria. As paredes, separadas da base por um marcado ângulo obtuso, são perfeitamente rectas e divergentes, configurando um depósito de secção trapezoidal com uma morfologia muito regular e marcadamente geométrica.

O bordo desta peça, plano e recto, encontra-se igualmente separado do corpo por uma inflexão muito marcada e angulosa, ainda que não assinalada exteriormente. A sua largura é relativamente regular, oscilando entre 1,3 e $1,6 \mathrm{~cm}$.

Esta lucerna conta ainda com um pico pouco desenvolvido (c 2,6 cm), de tendência trapezoidal e esquinas arredondadas, dotado de um orifício para a mecha de configuração igualmente trapezoidal que não chega a invadir a área do bordo. Este pico desenvolve-se grosso modo em linha com o bordo da lucerna, contribuíndo também ele para o aspecto linear e fortemente geométrico que caracteriza este exemplar em geral. A peça não conta com qualquer elemento de preensão.

As características morfológicas gerais desta peça indiciam, como já se avançou, a sua integração num ambiente produtivo grego arcaico. Os modelos de lucerna com depósito aberto, sem disco, são particularmente característicos do âmbito grego em geral, ao passo que certos aspectos formais, como o bordo comparativamente estreito, o pico pouco desenvolvido ou a ausência de elementos de preensão indiciam claramente a relativa antiguidade do exemplar do OSM.

Deve no entanto salientar-se que durante as suas etapas inicias, e apesar da existência de uma série de características gerais comuns como as que acabam de se enunciar, a produção lychnológica grega se caracteriza por uma considerável diversidade e falta de normalização. Torna-se por isso difícil estabelecer uma classificação operativa do material, particularmente quando este apresenta características formais mais raras ou peculiares como no caso que aqui nos ocupa. 


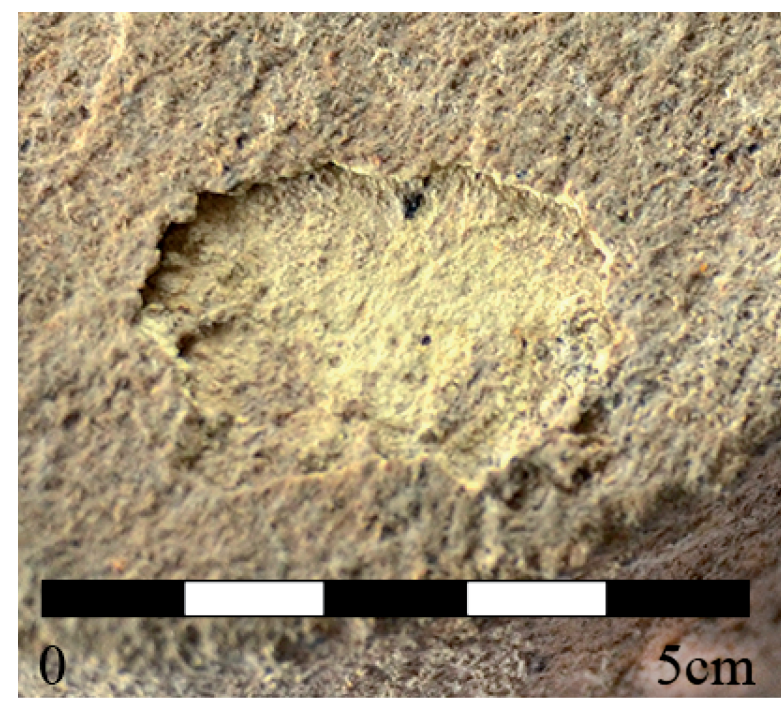

Figura 3. Detalhe da pasta da lucerna do OSM.

A integração da lucerna do OSM nos principais quadros tipológicos em uso para a classificação das lucernas gregas arcaicas e/ou clássicas (Broneer 1930, Howland 1958, Galli 2004) constitui, portanto, uma tarefa complexa, mas parece ainda assim possível estabelecer algumas comparações úteis para a correcta valorização desta peça.

Assim, e de forma tentativa, o exemplar alcacerense pode aproximar-se do Tipo III de Broneer (1930: 38-39) com o qual partilha alguns traços morfológicos, nomeadamente o reservatório muito aberto, o bordo tendencialmente plano ou a forma geral do pico. Com efeito, a morfologia da lucerna em apreço aproxima-se significativamente do perfil 14 definido por aquele autor (ibd.: fig. 14).

Peças de perfil similar encontram-se também documentadas na Ágora de Atenas, tendo sido classificadas por R. H. Howland como variantes do seu Tipo 12 (Howland 1958: 27, especialmente o n. 81). Este tipo considera-se contudo comparável ao Tipo II de Broneer (1930: 35-38), equivalência que no caso do perfil que aqui nos ocupa não parece totalmente evidente. Algumas peças de origem siciliana conservadas nos acervos do Museu Britânico e classificadas também elas no referido Tipo 12 de Howland apresentam igualmente similitudes com a peça em análise (Bailey 1975: 301, n. Q 639; 303-4, n. Q 645).

A peça do OSM pode, por outro lado, aproximar-se do Tipo 6, variante b de V. Galli (2004: 48-49), considerado equivalente ao já referido exemplar n. 81 da Ágora de Atenas. Segundo esta autora, esta variante tem origem na Grécia de Leste, tendo-se difundido na Grécia Continental e nas colónias ocidentais, onde o modelo terá sido localmente imitado (ibd: 48; v. tb. Bailey 1975: 300, 303-304).

Finalmente, caberia assinalar a presença nas colecções do Museo Civico Archeologico de Bologna estudadas por M. C. Gualandi Genito (1977) de uma peça com um perfil muito similar à que aqui nos ocupa (ibd: 34 , n. 10), classificada neste caso como pertencendo ao Tipo IV de Broneer (1930: 39-42).

A peça do OSM apresenta, contudo, algumas diferenças com respeito aos exemplares reunidos nestes grupos tipológicos, nomeadamente um aspecto mais marcadamente geométrico e uma total ausência de pé. De igual modo, a porção conservada da concavidade central da base não sugere a priori a existência de um cone central desenvolvido, característica geralmente presente nos tipos antes citados.

O ângulo externo do bordo não é, por outro lado, proeminente, característica que poderia aproximar esta peça do Tipo II de Broneer (1930: 35-38), sugerindo assim uma posição de certa forma intermédia entre este e o já citado Tipo III. Os Tipos I a IV de Broneer formam, de resto, uma família tipológica estreitamente interrelacionada entre si, o que nem sempre facilita a diferenciação entre os vários tipos concretos.

Assim, e apesar das ligeiras discrepâncias morfológicas antes comentadas - que, como referido, se podem justificar pela escassa estandardização da produção lychnológica grega arcaica - a adscrição da peça em apreço a este âmbito tipológico global parece clara. As características produtivas e, até certo ponto, decorativas, parecem igualmente suportar essa atribuição.

A lucerna em estudo apresenta, do ponto de vista da estrutura física, uma pasta calcária, relativamente compacta e bem depurada (fig. 3). Apesar de contar com escassos elementos não-plásticos - em particular nódulos de calcite e areias quartzíticas, de dimensões reduzidas - apresenta uma superfície de aspecto relativamente áspero. A cozedura, perfeitamente regular, parece ter-se realizado em ambiente oxidante, resultando em superfícies com uma tonalidade beige amarelada muito homogénea.

As superfícies não apresentam, no geral, marcas evidentes de nenhum tratamento particular. Não obstante, e apesar da existência de concreções que dificultam a observação da superfície, parece observar-se algum tipo de revestimento de tonalidade alaranjada aplicado sobre o bordo (fig. 2). O estado de conservação muito deficiente deste revestimento não permite 
assegurar se se trataria de uma aguada/ engobe ou mais propriamente de um verniz.

As características produtivas desta peça parecem assim compatíveis com as das lucernas de produção local coríntia, cujas pastas se descrevem como «...of a pale yellow colour (...) fine and well worked, with almost no sand and gritty substance, and (...) absolutely free from mica» (ibd: 34). Essas características aproximam-se também das da já citada peça n. 81 da Ágora de Atenas, considerada uma possível importação de Corinto (Howland 1958: 27).

As peças de Gravisca, em contrapartida, apresentam pastas com características muito distintas, atribuídas a centros produtores da Grécia de Leste (Galli 2004: 48), aos quais se poderia também adscrever a peça do Museu de Bolonha antes comentada (Genito 1977: 34).

Do ponto de vista decorativo, e como já houve oportunidade de comentar, a peça em estudo não conserva restos particularmente expressivos do revestimento que outrora terá possuído. Os vestígios preservados parecem contudo, também eles, compatíveis com o tipo de verniz alaranjado/ acastanhado considerado característico das produções coríntias (Broneer 1930: 38, Howland 1958: 27), situando-se além do mais sobre o bordo, zona onde tipicamente se aplica o verniz nas lucernas dos tipos antes comentados (Broneer 1930: 38, Howland 1958: 27; v. tb. Galli 2004: 48).

Assim, e com todas as devidas reservas resultantes das suas peculiaridades, a lucerna do OSM pode considerar-se uma produção grega arcaica, muito provavelmente coríntia. Morfológicamente, deve integrar-se na mais antiga família tipológica dentro do repertório lychnológico grego, formado pelos Tipos I a IV de Broneer (1930), aproximando-se em particular do Tipo II e especialmente do Tipo III (ibd: 35-39). Os paralelos mais específicos anteriormente enunciados permitem contudo estabelecer uma aproximação mais exacta ao seu enquadramento cronológico.

Com efeito, e independentemente das ligeiras discrepâncias ao nível da suas respectivas equivalências, já comentadas, o Tipo III de Broneer, as variantes do Tipo 12 de Howland e a variante $6 \mathrm{~b}$ de Galli compartem grosso modo as mesmas balizas cronológicas, produzindo-se entre o último terço do século VI e os inícios do V a.n.e. (Broneer 1930: 39, Howland 1958: 27 , Galli 2004: 48). A peça do OSM deverá também atribuir-se a esse mesmo intervalo de tempo, facto aliás confirmado pelo seu contexto primário, que seguidamente se procurará reconstruir.

\section{O CONTEXTO: A SEPULTURA 98 DO OSM}

Como já foi mencionado, a lucerna que temos vindo a analisar foi exumada por Vergílio Correia durante a última campanha de escavação por si conduzida no OSM em 1927. Mais concretamente, esta peça provém de um contexto sepulcral designado por aquele investigador como Sepultura 98.

Ao contrário de outros raros contextos, esta sepultura não mereceu qualquer menção na importante síntese publicada pelo Professor da Universidade de Coimbra no ano seguinte (Correia 1972 [1928]), pelo que a priori desconhecemos as suas características específicas. Não obstante, o estudo exaustivo da cultura material do OSM recentemente levado a cabo (Gomes 2016) permitiu identificar um conjunto significativo de materiais atribuídos a esta sepultura (fig. 4), repartidos pelo MDIA (cerâmicas) e pelo Museu Nacional de Arqueologia (metais), o que possibilita uma aproximação ao seu enquadramento cronológico e à sua posição na sequência global da necrópole.

Além da lucerna objecto do presente estudo, o espólio votivo da Sepultura 98 incluía também uma jarra de cerâmica cinzenta polida (fig. 4, n.1). Esta peça, enquadrada na Forma VI.1 da cerâmica cinzenta do OSM (Gomes 2016: 164 e est. XXXII, n. 434), apresenta um corpo globular separado do colo, alto e côncavo, por um ressalto bem marcado. Esse colo culmina num bordo triangular extroverso, ao passo que o fundo se encontra destacado por um pé de anel incipiente.

Esta peça pode comparar-se, até certo ponto, com a pequena jarra de Medellín recolhida na forma D7C da cerâmica cinzenta daquela necrópole, datada do último quartel do século VI a.n.e. (Lorrio 2008: 706). A peça alcacerense apresenta contudo algumas características morfológicas mais evolucionadas, como um incipiente pé de anel ou um colo com um perfil de aspecto moldurado, que a diferenciam deste exemplar extremenho.

Esta jarra não conta, com efeito, com paralelos próximos nos repertórios da cerâmica cinzenta do $\mathrm{Su}-$ doeste Peninsular, podendo contudo aproximar-se de algumas peças de cerâmica comum fina provenientes da área Ibérica, nomeadamente de El Cigarralejo (Cuadrado 1987: fig. 8) e de Los Villares (Blánquez 1990: fig. 38).

Estes paralelos, somados aos detalhes morfológicos tendencialmente tardios antes comentados parece sugerir uma cronologia relativamente avançada para esta peça do OSM, que pode datar-se já do século $\mathrm{V}$ a.n.e..

Entre o material da sepultura 98 contam-se igualmente alguns elementos relacionados com a 

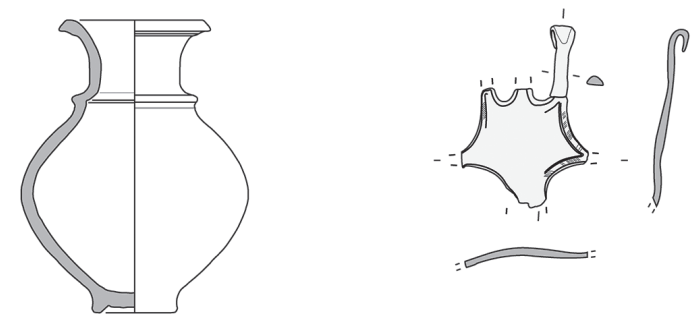

2

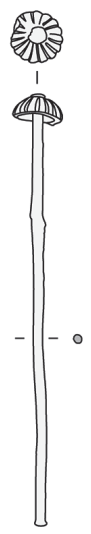

4
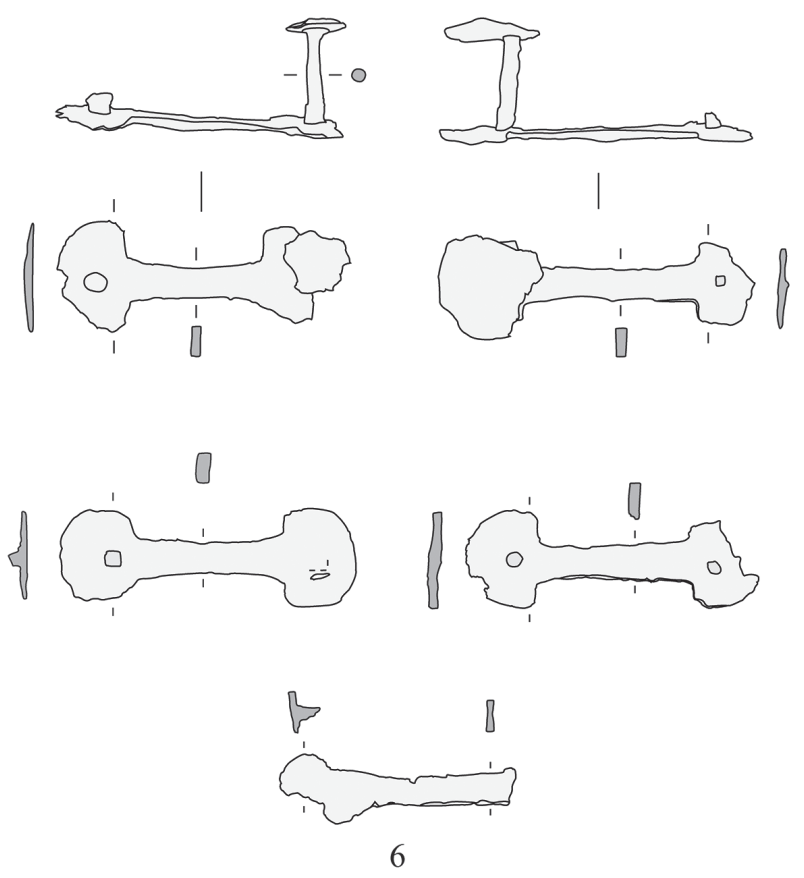

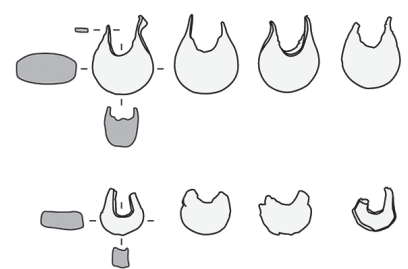

3
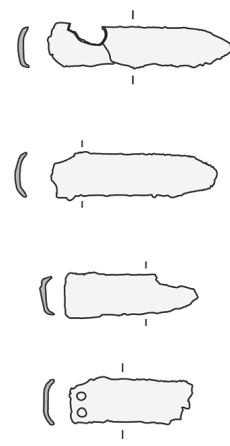

5
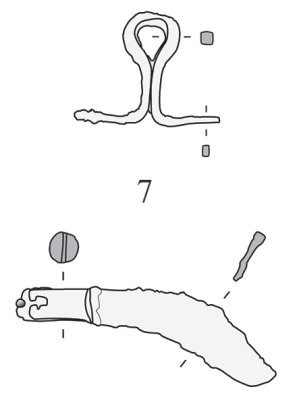

8

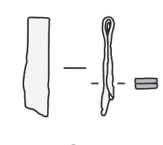

9

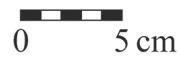

Figura 4. Materiais da Sepultura 98 do OSM. 
indumentária e o adorno. Entre estes merece destaque um fragmento da peça activa de um fecho de cinturão de tipo dito "céltico" (fig. 4, n. 2). Apesar de muito incompleta, esta peça parece ter contado originalmente com chanfraduras fechadas e três garfos, ostentando ainda uma decoração incisa junto ao rebordo. Enquadra-se portanto no tipo DIII3 de Cerdeño (1978: 283), no tipo B3B3 de Lorrio (1997: 217) ou ainda, segundo a mais recente notação proposta por R. Graells e A. Lorrio (2017), no tipo 3.3.2?.?.?.?.2/3a.B.

Originalmente, as peças deste grupo foram datadas de um intervalo entre o final do século VI e o final do V a.n.e. (Cerdeño 1978: 283). Esta cronologia foi contudo objecto de uma revisão posterior, elevando-se a datação dos primeiros exemplares a meados do século VI a.n.e (Torres Ortiz 2002: 212-213), tal como sugerido pelos dados de Medellín (Badajoz) onde estes fechos, integrados no Tipo B2 daquela necrópole, se documentam entre os meados do século VI e os meados do V a.n.e. (López Ambite 2008: 521-523).

$\mathrm{Na}$ sepultura 98 recolheram-se igualmente vários fragmentos de um bracelete de tipo "xorca" ("ajorca"), destacando-se um conjunto de pendentes em forma de sanguessuga parcialmente ocos, englobáveis no Tipo B estabelecido para os exemplares do OSM (Gomes 2016: 255) (fig. 4, n. 3). Este tipo de bracelete, que conheceu uma ampla difusão geográfica, é particularmente frequente nos contextos da fachada atlântica peninsular (Maluquer 1957: 251-256, Schüle 1969: 214-215, Gomes e Domingos 1983, Abásolo et al. 2004: 136), ocorrendo sobretudo em contextos datados dos séculos VI e V a.n.e. (Piñel 1971), com eventuais perdurações na centúria seguinte.

Esta sepultura continha ainda, ao que tudo indica, um (ou mais) elemento(s) complexo(s) de mobiliário de que se conservam diversas componentes metálicas de distinta natureza. Porventura a mais característica entre estas é uma charneira de ferro com remate discóide decorado com uma roseta (fig. 4, n. 4), seguramente parte de uma banqueta funerária de tipo diphros. Esta peça integra-se na variante $4 \mathrm{~b}$ definida para as dobradiças recolhidas na já citada necrópole de Medellín, na qual se documenta em contextos datados entre os meados do século VI e os inícios do V a.n.e. (Jiménez Ávila 2008: 550).

Outros elementos poderão classificar-se como braçadeiras (grapas, na terminologia espanhola). Estas peças oblongas de ferro, de tendência rectangular com uma extremidade arredondada ou em ponta e de secção convexa (fig. 4, n. 5), enquadram-se no Grupo 3 da tipologia avançada para as peças do OSM
(Gomes 2016: 304). Os elementos deste grupo parecem especialmente adequados para a aplicação nas extremidades de elementos perecíveis, podendo além de elementos de fixação ter servido como remates.

Nesta sepultura recolheu-se ainda um conjunto de peças de ferro formadas por barras estreitas de secção rectangular com extremidades semicirculares largas e aplanadas, agrupadas em pares unidos entre si por hastes de secção circular (fig. 4, n. 6). Estes elementos, de difícil interpretação, poderão ter também formado parte deste(s) mesmo(s) elemento(s) de mobiliário. Idêntica interpretação se poderia avançar para um grampo (fig. 4, n. 7) e um prego de ferro igualmente exumados neste contexto.

Uma outra peça distintiva proveniente da Sepultura 98 corresponde a uma pequena faca afalcatada de uma tipologia relativamente invulgar (fig. 4, n. 8), individualizada como Tipo 3 b na seriação estabelecida para os exemplares do OSM (Gomes 2016: 276). Os paralelos disponíveis sugerem que as facas afalcatadas deste tipo se desenvolveram fundamentalmente durante os séculos VI e V a.n.e. (ibd, com bibliografia).

Finalmente, caberia ainda assinalar a presença entre o conjunto artefactual procedente deste sepulcro de uma pequena pinça de bronze de morfologia muito simples e algo tosca (fig. 4, n. 9), que remete com toda a probabilidade para o domínio dos cuidados corporais.

Como se pode apreciar pela enunciação realizada nas páginas precedentes, os vários elementos atribuídos à Sepultura 98 do OSM configuram um conjunto bastante coerente, nomeadamente do ponto de vista da sua datação. As balizas cronológicas dos elementos antes citados são genericamente coincidentes, e uma ponderação combinada das mesmas permite afirmar que a Sepultura 98 datará muito provavelmente do primeiro quartel do século $\mathrm{V}$ a.n.e.

Esta cronologia, como facilmente se apreciará, coincide perfeitamente com a datação intrínseca avançada para a lucerna aqui estudada, confirmando assim de forma cabal o enquadramento cronológico e, em certa medida, cultural acima proposto para esta peça.

Por outro lado, estas balizas cronológicas permitem situar a sepultura em apreço num momento avançado da Sub-fase Ib da sequência de utilização da necrópole (c 550 - 475/450 a.n.e.) (Gomes 2016: 346-347, Gomes no prelo), o que permite tecer algumas considerações adicionais sobre a tipologia específica deste conjunto sepulcral.

Com efeito, a Sub-fase Ib caracteriza-se precisamente pela simplificação e aparente homogeneização do panorama funerário do OSM, que passa a ser 
dominado de forma virtualmente exclusiva durante esta etapa pelas sepulturas de incineração in situ em fossa simples, de tipo busta, enquadráveis no $3^{\circ}$ Tipo estabelecido por Vergílio Correia (1972 [1928]).

Assim, e ainda que não contemos com uma descrição específica desta estrutura sepulcral em particular, parece verosímil que a sepultura que aqui nos ocupa corresponda a uma deposição integrável neste mesmo tipo, embora de características ao que tudo indica um tanto destacadas dada a comparativa riqueza dos espólios associados.

Essa riqueza encontra-se materializada, entre outros aspectos, na capacidade de aceder a circuitos comerciais supra-regionais e de adquirir um elemento como a lucerna aqui estudada que, apesar da sua simplicidade, deverá ter constituído um elemento exótico e putativamente prestigioso num contexto local/regional onde as importações gregas estão ainda longe de ser comuns (Arruda 2019; v. tb. Gomes 2017: fig. 3).

A inclusão deste elemento no espólio funerário desta sepultura pode entender-se como uma substituição das típicas "saucer lamps" fenício-púnicas, que parecem ter constituído parte integrante do pacote ritual próprio das sepulturas do $3^{\circ}$ Tipo (Correia 1972 [1928]: 176, v. tb. Gomes 2016: 330), por um elemento mais exótico e, portanto, mais prestigioso; o contexto de utilização desta peça não deixa, portanto, de se pautar pelas práticas e crenças funerárias locais. A sua singularidade deve no entanto interpretar-se como um símbolo mais do elevado estatuto do defunto ali depositado.

Os dados actualmente disponíveis não permitem tecer muito mais considerações sobre a identidade desse defunto e, por extensão, sobre a biografia da lucerna que o acompanhou na sua última morada. Com efeito, faltam-nos por completo os dados antropológicos que permitiriam estabelecer uma aproximação à sua idade ou mesmo ao seu género.

O espólio da sepultura poderá contudo oferecer-nos algumas pistas em relação a este último aspecto, na medida em que os fechos de cinturão de tipo "céltico" e as banquetas funerárias (diphros) surgem tendencialmente associados em várias necrópoles da I Idade do Ferro do Sudoeste a indivíduos masculinos (Almagro-Gorbea 2008, Arruda et al. 2017: 219-221, Graells e Lorrio 2017: 133-140).

Assim, e com todas as reservas decorrentes das limitações informativas já mencionadas, a lucerna em estudo parece ter acompanhado um indivíduo, possivelmente masculino, de elevado estatuto social. Este indivíduo - ou o seu grupo familiar - deteria, ao que tudo indica, os recursos necessários para aceder a circuitos comerciais de larga distância através dos quais obter um elemento tão exótico como aquele que nos ocupa. Esta lucerna materializa assim, no cenário da morte, a sua preeminência social, que contudo se expressa no quadro de umas práticas funerárias perfeitamente enraizadas e consagradas na tradição local.

\section{A LUCERNA DO OSM NO CONTEXTO DO COMÉRCIO GREGO ARCAICO COM O EXTREMO OCIDENTE: ALGUMAS OBSERVAÇÕES FINAIS}

O carácter excepcional da lucerna do OSM, enfatizado pelas considerações sobre a sua proveniência e o seu contexto cronológico tecidas nas páginas anteriores, impõe a necessidade de abordar, mesmo que de forma esquemática, a posição desta peça no âmbito do comércio grego arcaico com o Extremo Ocidente e o contexto no qual a mesma poderá ter chegado a Alcácer do Sal.

Com efeito, a presença desta peça em Alcácer do Sal não deixa de causar alguma estranheza já que as importações gregas arcaicas são sumamente raras no actual território português (Arruda 2019), resumindo-se na prática a um fragmento atribuído ao Coríntio Médio, do Castelo de Castro Marim (Arruda 2006: 135-136, n. 69), a dois fragmentos, também do Coríntio Médio, da Quinta do Almaraz (Almada) (Cardoso 2004: fig. 173), e a uma possível vicup ática de Lisboa (Arruda 1997: 86-7).

Mais interessante para o caso vertente é, contudo, a presença no próprio OSM de um recipiente ático de figuras negras, concretamente uma taça do tipo $\mathrm{C}$ de H. Bloesch (1940, apud Arruda, 2019) enquadrável no grupo das floral band-cups de J. Beazley (1978: 197, apud Arruda, 2019) e datável do primeiro quartel do século V a.n.e. (Arruda 2006: 136; Arruda 2019).

Esta peça, virtualmente contemporânea portanto da lucerna aqui estudada, confirma não apenas a capacidade da comunidade de Alcácer do Sal de aceder aos circuitos comerciais mediterrâneos através dos quais circularia a cerâmica grega arcaica, bem documentada noutros âmbitos do Ocidente Peninsular (v. Domínguez e Sánchez 2000, com bibliografia anterior; Cabrera e Santos 2001), como também as peculiaridades das suas pautas de consumo.

Tal como a lucerna que agora se apresenta, esta taça constitui com efeito um caso isolado no panorama das importações gregas arcaicas do Ocidente peninsular. A presença em Alcácer do Sal da peça que aqui nos ocupa não se encontra, portanto, totalmente desenquadrada, 


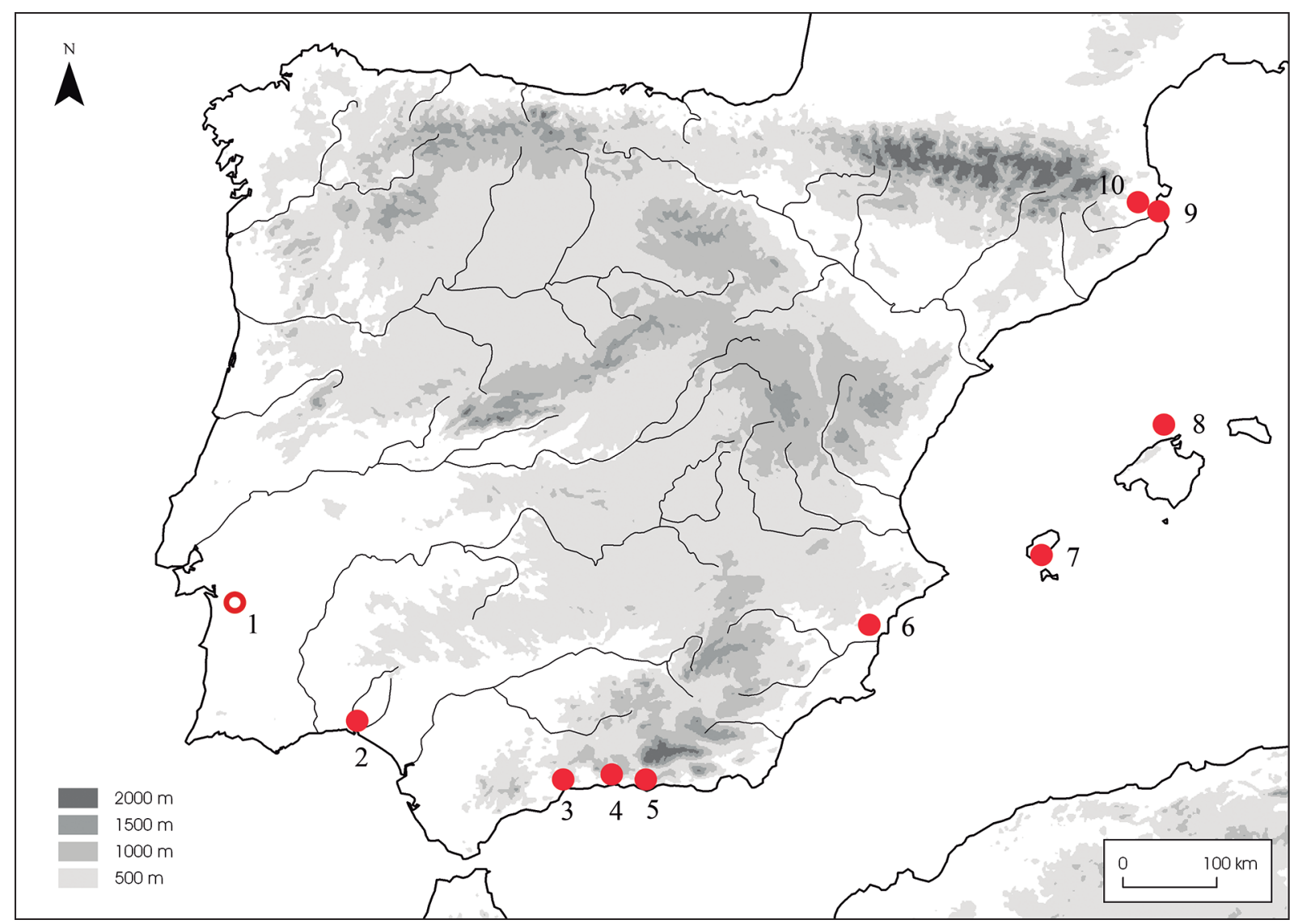

Figura 5. Distribuição geográfica das lucernas gregas arcaicas peninsulares mencionadas no texto: 1 - Olival do Senhor dos Mártires (Alcácer do Sal); 2 - Huelva; 3 - Málaga; 4 - Jardín (Vélez-Málaga); 5 - Puente de Noy (Almuñécar); 6 - Peña Negra (Crevillente); 7 - Puig des Molins (Ibiza); 8 - Cala Sant Vicenç (Mallorca); 9 - Empúries; 10 - Mas Castellar de Pontós (Alt Empordà).

posto que já anteriormente se documentou no sítio não apenas um recipiente de produção grega com uma datação similar mas, sobretudo, de natureza igualmente única (cf. Arruda 2019).

No entanto, o enquadramento desta lucerna no contexto do comércio grego arcaico peninsular merece algumas considerações adicionais. Desde logo, deve assinalar-se que a presença de lucernas entre os repertórios das mais antigas importações gregas na Península Ibérica não é particularmente comum.

Ainda assim, essa presença não é desconhecida (fig. 5), mesmo na área atlântica, conhecendo-se um lote significativo de lucernas arcaicas provenientes de escavações no Centro Histórico de Huelva (fig. 5, n. 2), geralmente atribuídas a produções da Grécia de Leste datáveis entre o século VI e os inícios do V a.n.e. (Cabrera 1989: fig. 9 nn. 159-162, fig. 13 nn. 254-261; Fernández Jurado1989: lám. CXXXIV n. 4, lám. CXXXIX n. 1; Garrido e Orta 1994: fig. 3, Cabrera e Sánchez
2000: 257 n. 31). Recentemente, a realização de análises arqueométricas permitiu também documentar uma produção local de lucernas de tipo grego arcaico, presumivelmente datável da primeira metade/ meados do século VI a.n.e. (González de Canales e Llompart 2017: n. 21).

A presença de lucernas gregas (e de tipo grego) arcaicas está também bem documentada no Centro Histórico de Málaga (Gran-Aymerich 1991: fig. 49, 5 - produção da Grécia de Leste) (fig. 5 n. 3), na necrópole de Jardín (Vélez-Málaga) (Schubart e Maass-Lindemann 1995: 126 - possíveis produções locais) (fig. 5 n. 4), na de Puente de Noy (Almuñécar) (Molina e Huertas 1986: fig. 4 n. 2 - possível produção local) (fig. 5 n. 5), bem como na Fase II do povoado da Peña Negra (Crevillente) (González Prats 1982: 95-96, fig. 1 nn. 3-4 - possíveis produções da Grécia de Leste) (fig. 5 n. 6).

Outro conjunto significativo de lucernas arcaicas foi ainda recolhido em Ibiza, na necrópole de Puig des Molins (fig. 5 n. 7), incluíndo sobretudo 
lucernas áticas de verniz negro (Sánchez 1981: 292296, figs. 6-7; Fernández et al. 1987: 20-29) mas também uma possível lucerna coríntia do Tipo IV de Broneer (Domínguez e Sánchez 2000: 83), e próxima portanto da família tipológica da peça que aqui nos ocupa. Ainda no âmbito do arquipélago balear cabe assinalar o exemplar recuperado no naufrágio de Cala Sant Vicenç, ao largo de Maiorca (fig. 5 n. 8), considerado neste caso uma produção da Magna Grécia (Nieto e Santos 2009: 89-92).

Finalmente, e como seria de esperar, na colónia grega de Emporion e na sua área de influência as peças deste tipo estão também relativamente bem representadas. Em Ampúrias (fig. 5 n. 9), com efeito, estão documentadas tanto produções áticas como gregas ocidentais (Domínguez e Sánchez 2000: 68-70), a que podem somar-se - sem pretensões de exaustividade - um exemplar da Grécia de Leste e outro grego ocidental de Ullastret (Ugolini 1993: 286) e um exemplar de Mas Castellar de Pontós (Asensio et al. 2017: fig. 2 n.17) (fig. 5 n. 10).

Caberia por outro lado salientar que a escassez de lucernas gregas arcaicas parece extensível ao território meridional francês (Ugolini 1993), excepção feita, como é natural, aos núcleos propriamente gregos ou com uma forte presença grega, como Marselha (Villard 1960: 45) ou Arles (Ugolini 1993: 284). Saliente-se, contudo, a presença de um lote de lucernas áticas ou da Grécia de Leste no naufrágio grego arcaico de Pont Lequin 1 (Long et al. 1992: 217-218 e fig. 37), associado a um conjunto de floral band cups muito similares à do OSM, antes comentada (ibd: 209).

Apesar destas ocorrências, não deve obviar-se o facto de até ao momento não se terem documentado na Península Ibérica nem nos territórios adjacentes lucernas morfologicamente comparáveis à do OSM. Igualmente problemática é a ausência de referências claras a lucernas de produção coríntia ou assimilável, excepção feita ao possível exemplar ebusitano (Domínguez e Sánchez 2000: 83). Com efeito, e como ficou patente na enunciação antes realizada, as produções da Grécia de Leste (e, em menor medida, as produções áticas) são totalmente predominantes entre as lucernas gregas arcaicas peninsulares, o que reforça o carácter isolado e excepcional da peça aqui apresentada.

No entanto, e apesar da extrema raridade das lucernas coríntias no Ocidente, não pode deixar de se assinalar que as produções coríntias em geral não são de modo algum desconhecidas na Península Ibérica, sendo relativamente frequentes os pequenos recipientes de perfume (Rouillard 1991, Domínguez e
Sánchez 2000: 86), mas também produtos de outra natureza, nomeadamente anfórica (Domínguez e Sánchez 2000: 88).

Como ficou referido, a presença de cerâmicas coríntias de figuras negras encontra-se também documentada em Portugal, mesmo que de forma residual (Cardoso 2004: fig. 173, Arruda 2006: 135-6 n. 69, Arruda 2019). Estes elementos, datados do Coríntio Médio, são contudo significativamente mais antigos do que a lucerna aqui apresentada e pertencem a fluxos comerciais de natureza sem dúvida muito distinta.

No período que aqui nos ocupa, em contrapartida, os produtos coríntios são de uma forma geral bastante residuais no território peninsular, reduzindo-se a alguns exemplares de ânforas Coríntias A e B recolhidos em contextos de finais do século VI ou de inícios do V a.n.e. (Pellicer et al. 1983: 89, Fernández Izquierdo et al. 1989: 608-609, Abad e Sala 1993: 203, Cabrera 1995: 391, Aquilué et al. 2001: 329; see also Muñoz 1996: 82) e a um vaso plástico exumado no centro histórico de Huelva, datado também ele desses momentos (Cabrera e Sánchez 2000: 251 n. 25).

Assim, e ainda que desconheçamos o modo ou as vias específicas pelos quais a lucerna aqui estudada (ou, por sinal, a floral band cup ática antes comentada) alcançou Alcácer do Sal, a presença desta invulgar peça parece poder enquadrar-se no quadro mais amplo da circulação de produtos gregos tardo-arcaicos em geral, e coríntios em particular, que, apesar de residual, se encontra ainda assim bem atestada.

Não é por outro lado impossível que a futura publicação dos abundantes materiais ainda inéditos provenientes de escavações em vários pontos do povoado de Alcácer do Sal venham permitir uma melhor contextualização das importações gregas arcaicas do OSM.

Em todo caso, a presença desta peça neste contexto do Extremo Ocidente afigura-se em si mesma como um dado do maior interesse em face da escassez de lucernas gregas arcaicas na Península Ibérica e do absoluto desconhecimento das mesmas no território português, onde a cerâmica grega arcaica é, como vimos, francamente rara (Arruda 2019).

Por outro lado, o estudo desta peça vem reforçar a imagem de Alcácer do Sal como um enclave que deteve, ao longo de toda a sua diacronia sidérica, uma considerável conexão com as redes que unem o território actualmente português à bacia do Mediterrâneo. A lucerna aqui estudada representa portanto um importante dado adicional para a restituição dos processos históricos da comunidade que durante o I milénio a.n.e. ocupou este núcleo do Baixo Sado. 


\section{Agradecimentos}

Gostaria de expressar o meu agradecimento ao Instituto de Arqueologia da Faculdade de Letras da Universidade de Coimbra, na pessoa da Professora Doutora Raquel Vilaça, por todas as facilidades concedidas no acesso a esta e às demais peças de Alcácer do Sal ali depositadas. Agradeço também à Professora Doutora Ana Margarida Arruda e ao Doutor Carlos Pereira pelos seus úteis comentários a uma versão prévia deste trabalho.

O presente artigo foi realizado no contexto do Projecto de Pós-Doutoramento "Made in the Mediterranean: consumo, identidade e economia política no Bronze Final e na I Idade do Ferro do Sul de Portugal" financiado pela Fundação para a Ciência e Tecnologia (Portugal) através da Bolsa de Pós-Doutoramento SFRH/BPD/115343/2016.

\section{BIBLIOGRAFIA}

Abad, L. e Sala, F. (1993): El poblado ibérico de El Oral (San Fulgencio, Alicante). Valencia, Universidad de Valencia.

Abásolo, J.-A.; Ruiz Vélez, I. e Rodríguez, A. (2004): "El conjunto arqueológico de Alto de Rodilla (Monasterio de Rodilla, Burgos)". Boletín del Seminario de Estudios de Arte y Arqueología 69-70: $115-$ 146.

Aquilué, X.; Castanyer, P.; Santos, M. e Tremoleda, J. (2001): "Les ceràmiques gregues arcaiques de la Palaià Polis d'Empòrion", em P. Cabrera e M. Santos (eds.), Ceràmiques jònies d'època arcaica: centres de producció i comercialització al Mediterrani Occidental. Actes de la Taula Rodona celebrada a Empúries, els dies 26 al 28 de maig de 1999: 285 346. Empúries (1999), Barcelona, Museu d'Arqueologia de Catalunya.

Arruda, A. M. (2006): "Cerâmicas gregas encontradas em Portugal”, em Vasos Gregos em Portugal. Aquém das Colunas de Hércules: 135-149. Lisboa, Museu Nacional de Arqueologia.

Arruda, A. M. (2019): "A cerâmica grega arcaica do território actualmente português". Archivo Español de Arqueología 92: 19-25. DOI: <http://doi. org/10.3989/aespa.092.019.002>.

Asensio, D.; Pons, E.; Jornet, R. e Morer, J. (2017): "Aportación de la cerámica griega fina y sus contextos cerámicos a la caracterización de la secuencia de asentamientos superpuestos entre el siglo VI y el siglo IV a. C. en el Mas Castellar de Pontós
(Alt Empordà, Girona)", em X. Aquilué, P. Cabrera e M. Orfila (eds.), Homenaje a Glòria Trias Rubiés. Cerámicas griegas de la Península Ibérica: cincuenta años después (1967-2017): 124-139. Empúries, Centro Iberia Graeca. URL: <https://www.iberiagraeca.net/otros/Libro_Homenaje_Gloria.pdf> [consultado a 20/07/2018].

Bailey, D. M. (1975): A Catalogue of the lamps in the British Museum. 1. Greek, Hellenistic and early Roman pottery lamps. Londres, British Museum.

Beazley, J. (1978): Attic Black-Figure Vase-Painters. Oxford, Oxford University Press.

Blánquez, J. (1990): La formación del mundo ibérico en el Sureste de la Meseta. Estudio arqueológico de las necrópolis ibéricas de la provincia de Albacete. Albacete, Diputación Provincial de Albacete.

Bloesch, H. (1940): Formen attischer Schalen. Berna, Benteli.

Brito, M. A. de A. e (1968): Contributo para a classificação de alguns achados de Alcácer do Sal (Época Pré-Romana). Tese de Licenciatura, Universidade de Coimbra. Inédita.

Broneer, O. (1930): Corinth. Volume IV, Part II, Terracotta Lamps. Cambridge, Harvard University Press.

Cabrera, P. (1989): "El comercio foceo en Huelva: cronología y fisionomía". Huelva Arqueológica 10-11: 41-100.

Cabrera, P. (1995): “Cerámicas griegas en Tartessos: su significado en la costa meridional de la Península desde Málaga a Huelva", em Tartessos: 25 años después, 1968-1993. Actas del Congreso Conmemorativo del V Symposium Internacional de Prehistoria Peninsular: 387-399. Cádiz (1993), Jerez de la Frontera, Ayuntamiento de Jerez de la Frontera.

Cabrera, P. e Sánchez, C. (2000): "El comercio griego con el mundo ibérico durante la época clásica", em Los Griegos en España: tras las huellas de Heracles: 133-148. Madrid, Museo Arqueológico Nacional.

Cabrera, P. e Santos, M. (2001) (eds.): Ceràmiques jònies d'època arcaica: centres de producció $i$ comercialització al Mediterrani occidental. Barcelona, Museu d'Arqueologia de Catalunya.

Cardoso, J. L. (2004): A Baixa Estremadura, dos finais do IV milénio a.C. até à chegada dos Romanos: um ensaio de História Regional. Oeiras, Centro de Estudos Arqueológicos de Oeiras.

Cerdeño, Mª L. (1978): "Los broches de cinturón peninsulares de tipo céltico". Trabajos de Prehistoria 35: 279-307.

Correia, V. (1972 [1925]): "Uma conferência sobre a Necrópole de Alcácer do Sal", em Obras. Volume 
IV, Estudos Arqueológicos: 151-168. Coimbra, Universidade de Coimbra.

Correia, V. (1972 [1928]): “Escavações realizadas na Necrópole Pré-Romana de Alcácer do Sal em 1926 e 1927”, em Obras. Volume IV, Estudos Arqueológicos: 169-179. Coimbra, Universidade de Coimbra.

Cuadrado, E. (1987): La necrópolis ibérica de El Cigarralejo (Mula, Murcia). Madrid, Real Academia de la Historia.

Domínguez, A. e Sánchez, C. (2000): Greek Pottery in the Iberian Peninsula. Leiden, Brill.

Fernández, J. H.; Maluquer, J. e Picazo, M. (1987): Corpus Vasorum Antiquorum. Espagne, Fascicule 6. Musée d'Eivissa. Barcelona, Institut d'Estudis Catalans.

Fernández Jurado, J. (1989): Tartessos y Huelva. Huelva, Diputación Provincial de Huelva.

Fernández Izquierdo, A.; Gómez, C. e Ribera, A. (1989): “Ánforas griegas, etruscas y fenicias del yacimiento submarino de Cabanyal-Malvarrosa (Valencia)", em Crónica del XIX Congreso Nacional de Arqueología: 607-617. Valencia (1987), Zaragoza, Universidad de Zaragoza.

Frankenstein, S. (1997): Arqueología del colonialismo. El impacto fenicio y griego en el sur de la Península Ibérica y el suroeste de Alemania. Barcelona, Editorial Crítica.

Galli, V. (2004): Gravisca. Scavi nel Santuario Greco. Le lucerne greche e locali. Bari, Edipuglia.

Garrido, J. P. e Orta, E. M. (1994): El habitat antíguo de Huelva (Periodos Orientalizante y Arcaico). La primera excavación en la Calle del Puerto. Madrid, Instituto de Conservación y Restauración de Bienes Culturales.

Genito, M. C. G. (1977): Lucerne fittili delle collezioni del Museo civico archeologico di Bologna. Bologna, Istituto per la Storia di Bologna.

Gomes, F. B. (2016): Contactos culturais e discursos identitários na I Idade do Ferro do Sul de Portugal (séculos VIII - V a.n.e.): leituras a partir do registo funerário. Tese de Doutoramento. Universidade de Lisboa. Inédita. URL: <http://hdl.handle. net/10451/25042> [consultado a 20/07/2018].

Gomes, F. B. (2017): “Un conjunto de cerámicas áticas inéditas de la necrópolis de Olival do Senhor dos Mártires". Onoba 5: 45-58. URL: <http://www. uhu.es/publicaciones/ojs/index.php/onoba/article/ view/3122/2874> [consultado a 20/07/2018].

Gomes, F. B. (no prelo): "A evolução dos rituais funerários da Idade do Ferro no Ocidente Peninsular: uma nova proposta de faseamento para a necrópole do Olival do Senhor dos Mártires (Alcácer do Sal)". O Arqueólogo Português S.5:6.

Gomes, J. J. F. e Domingos, J. B. B. (1983): “A 'xorca' da Serra das Ripas (Alenquer)". O Arqueólogo Português S.4:1: 287-300.

González de Canales, F. e Llompart, J. (2017): "Producción de cerámicas griegas arcaicas en Huelva". Archivo Español de Arqueología 90: 125-145. DOI: $<$ http://doi.org/10.3989/aespa.090.017.006>.

González Prats, A. (1982): "El componente tipológico griego en el ambiente cerámico de Peña Negra II (675-650 A.C.)". Lucentum I: 93-113.

Graells, R. e Lorrio, A. (2017): Problemas de cultura material: Broches de cinturón decorados a molde de la Península Ibérica (s. VII-VI A.C.). Alicante, Universidad d'Alacant.

Gran-Aymerich, J. (1991): Málaga Phénicienne et Punique: Recherches franco-espagnoles 1981-1988. Paris, Éditions Recherches sur les Civilisations.

Howland, R. H. (1958): Athenian Agora. Volume IV, Greek Lamps and their survivals. Princeton, The American School of Classical Studies at Athens.

Jiménez Ávila, J. (2008): "Grapas y charnelas de diphroi”, em M. Almagro-Gorbea (dir.), La necrópolis de Medellín. II. Estudio de los hallazgos: 542552. Madrid, Real Academía de la Historia.

Long, L.; Miro, J. e Volpe, G. (1992): "Les épaves archaïques du Point Lequin (Porquerolles, Hyères, Var). Des donnés nouvelles sur le commerce de Marseille à la fin du VIe et dans la première moitié du Ve s. av. J.C.", em M. Bats, G. Bertucchi, G. Congès e H. Tréziny (eds.), Marseille Grecque et la Gaule. Actes du colloque international, Marseille, 18-23 novembre 1990: 199-234. Marselha (1990), Lattes/ Aix-en-Provence, ADAM éditions/ Université de Provence.

López Ambite, F. (2008): "Broches de cinturón", em M. Almagro-Gorbea (dir.), La necrópolis de Medellín. II. Estudio de los hallazgos: 514-528. Madrid, Real Academía de la Historia.

Lorrio, A. (1997): Los Celtiberos. Madrid, Universidad Complutense de Madrid.

Lorrio, A. (2008): “Cerámica gris”, em M. Almagro-Gorbea (dir.), La necrópolis de Medellín. II. Estudio de los hallazgos: 673-723. Madrid, Real Academía de la Historia.

Maluquer, J. (1957): "Un interesante lote de bronces, hallado en el castro de Sanchorreja (Avila)". Zephyrus VIII: 241-256.

Molina, F. e Huertas, C. (1986): Almuñécar en la Antiguedad. La necrópolis fenicio-púnica de Puente de Noy II. Granada, Caja Provincial de Granada. 
Muñoz, Á. (1996): "Secuencia histórica del asentamiento fenicio-púnico de Cádiz: un análisis crono-espacial tras quince años de investigación arqueológica". Boletín del Museo de Cádiz 7: 77-105.

Nieto, X. e Santos, M. (2009): El vaixell grec arcaic del pecio de Cala Sant Vicenç. Barcelona: Museu d'Arqueologia de Catalunya.

Pellicer Catalán, M.; Escacena Carrasco, J. L. e Bendala Galán, M. (1983): El Cerro Macareno. Madrid, Ministerio de Cultura.

Paixão, A. C. (1970): A necrópole do Senhor dos Mártires, Alcácer do Sal. Novos elementos para o seu estudo. Tese de Licenciatura, Universidade de Lisboa. Inédita.

Piñel, C. (1976): "Materiales del poblado de Las Paredejas, en el Cerro del Berrueco. Una nueva arracada". Zephyrus XXVI-XXVII: 351-368.

Ponte, S. da (1985): "Algumas fíbulas de Alcácer do Sal”. O Arqueólogo Português S.4:3: 137-154.

Rouillard, P. (1991): Les Grecs et la Péninsule Ibérique: du VIIIe au IVe siècle avant Jésus-Christ. Paris, Diffusion du Boccard.

Rouillard, P.; Paixão, A. C.; Villanueva-Puig, M.-C. e Durand, J.-L. (1989): “Les vases grecques d'Alcácer do Sal”. O Arqueólogo Português S.4:6-7: 43-108.
Sánchez, C. (1981): "La cerámica ática de Ibiza en el Museo Arqueológico Nacional". Trabajos de Prehistoria 38: 281-311.

Schubart, H. e Maass-Lindemann, G. (1995): "Informe de las excavaciones en la necrópolis de Jardín (Vélez-Málaga, Málaga)". Cuadernos de Arqueología Mediterránea 1: 57-213.

Schüle, W. (1969): Die Meseta-kulturen der Iberischen Halbinsel: Mediterrane und Eurasische elemente in früheisen zeitlichen kulturen südwesteuropas. Berlim, Walter de Gruyter \& Co.

Torres Ortiz, M. (2002): Tartessos. Madrid, Real Academia de la Historia.

Ugolini, D. (1993): "Lampes grecques et de type grec de Béziers. Utilisation et diffusion de la lampe grecque dans le Midi entre le VIe et le IVe siècle avant J.-C.". Documents d'Archéologie Méridionale 16: 279-293.

Vilaça, R. (ed.) (2016): O Instituto de Arqueologia: fragmentos da sua colecção. Coimbra, Imprensa da Universidade de Coimbra. DOI: <http://dx.doi. org/10.14195/978-989-26-1124-2>

Villard, F. (1960): La céramique grecque de Marseille (VIe - IVe s.). Essai d'histoire économique. Paris, Éditions du Boccard. 
